\title{
A Preliminary Study on the Guidance of Spatial Planning for Tourist Towns under the Background of Rural Revitalization-Taking Sanjiang Town as an Example
}

\author{
Fei Wang, Xiang Zhao \\ School of Civil Engineering and Architecture, Southwest University of Science and Technology, Mianyang, Sichuan \\ Email: 952142430@qq.com
}

How to cite this paper: Wang, F., \& Zhao, X. (2021). A Preliminary Study on the Guidance of Spatial Planning for Tourist Towns under the Background of Rural Revitalization-Taking Sanjiang Town as an Example. Current Urban Studies, 9, 597-608. https://doi.org/10.4236/cus.2021.93036

Received: August 29, 2021

Accepted: September 20, 2021

Published: September 23, 2021

Copyright (อ 2021 by author(s) and Scientific Research Publishing Inc. This work is licensed under the Creative Commons Attribution International License (CC BY 4.0).

http://creativecommons.org/licenses/by/4.0/

\section{(c) (i) Open Access}

\begin{abstract}
With the proposal of the rural revitalization strategy, tourist towns have sprung up like mushrooms after rain, but their rapid development has brought about disorder expansion of space, insufficient ecological protection, space fragmentation, low space efficiency, and uneven distribution of public service facilities. Problems such as uniformity, dilapidated living space, and poor overall town quality are affecting the further development of tourist towns. Taking Sanjiang Town as an example, this paper summarizes the development process and characteristics of small tourist towns in Northwest Sichuan through literature research and field research. The results of the general environment and on-site questionnaire surveys put forward development ideas and spatial planning guidance measures for tourist towns, in order to provide three rivers plans and ideas for the development of tourist towns under rural revitalization.
\end{abstract}

\section{Keywords}

Rural Revitalization, Small Tourist Towns, Spatial Planning

\section{Introduction}

Since the $19^{\text {th }}$ National Congress of the Communist Party of China adopted the strategy of rural revitalization as a national strategy, the idea of developing productivity and consolidating the economic foundation has penetrated into major villages and towns (Liu et al., 2019). In order to change the current agricultural and rural areas from insufficient total to structural contradictions, some villages 
and towns have begun to target rural revitalization strategies, and accelerate the transformation of agricultural and rural areas into new industries and formats such as rural tourism, leisure agriculture, and sightseeing agriculture, and strive to build modern agriculture. Industry-university-tourism integration development system promotes rural revitalization and development. However, this has brought many problems to urban space, society, environment, and life, such as disorderly expansion, insufficient ecological protection, space fragmentation, low space efficiency, uneven distribution of public service facilities, dilapidated living space, and overall. The quality of towns is poor, etc.

For this reason, many scholars believe that: with rural revitalization as a strategic guide, guiding cities and towns toward compact space, high efficiency, orderly, production development, ecological harmony, and affluent life, and achieving sustainable development of cities and towns has become an important mission of current urban construction (Seminar, 2018).

\section{Tourist Towns}

Tourism-oriented towns refer to towns that take tourism income as the main source of income, and their tourism output value accounts for a high proportion of the labor force engaged in the tourism service industry (Zhang, 2020). These towns generally have good natural resources or human resources, and the tourism industry is relatively developed. Generally, the government or tourist attractions lead the gradual development of cities and towns, and make full use of their resource advantages (Tao \& Qiu, 2020).

At the same time, the development of tourism has brought many problems to the development of villages and towns. For this reason, in the context of rural revitalization, tourist towns should re-examine their own development advantages and the current development environment, seize the policy opportunities of rural revitalization, actively promote the integrated development of the tourism industry and other industries, and promote the further deregulation of the urban development model. Change and take a sustainable development path that is ecologically livable, industrially prosperous, and ecologically harmonious in line with its own development.

To this end, this article takes Sanjiang Town as an example, analyzes its spatial problems through the discussion of its spatial development history and characteristics, and proposes development strategies and spatial planning guidance measures based on the rural revitalization strategy.

\section{The Development History and Characteristics of Urban Space in Sanjiang Town}

Sanjiang Town is located in the southwest of Wenchuan County in the Aba Tibetan and Qiang Autonomous Prefecture. It is a tributary of the Minjiang River and the upper reaches of the Shoujiang River. The West River, Zhonghe River and Heishi River converge at the center of the town and converge at Shoujiang, 
hence the name Sanjiang (Pan, 2000). It has 6 administrative villages under its jurisdiction and the town covers an area of 485.22 square kilometers (Sanjiang, 2021). The town has a registered population of 4018 people, a total of 1147 households, mainly Han and Tibetan populations (Sanjiang, 2021). The per capita net income of the town in 2019 was 18,577.9 yuan (Sanjiang, 2021).

\subsection{The Development History of Urban Space}

The development of the urban space in Sanjiang Town is mainly affected by natural disasters. Before the Wenchuan earthquake, the urban space in Sanjiang Town consisted of buildings around the old street of Jie Cun and Xihe. After the Wenchuan earthquake, the town was severely affected and most of the buildings collapsed. After relocation and unified planning and reconstruction, combined with the post-disaster Wenchuan special tourist area planning, the main urban space composed of the original town and the Tibetan village of the water village of Lehuo Village has been formed. Affected by floods in 2019, Sanjiang Town was severely affected, riverside facilities in the town were washed away, river bank slopes and infrastructure were severely damaged, and the urban environment and safety urgently need to be strengthened and improved.

\subsection{Spatial Development Characteristics}

\subsubsection{Scale of Cities and Towns: Rapid Gathering to Slow Growth}

The development of the urban space in Sanjiang Town is divided into three stages. Before the Wenchuan earthquake, the urban space of Sanjiang Town was in an autonomous and disorderly development stage, with a small urban population and small settlements. After the Wenchuan earthquake, after relocation planning and reconstruction, the urban space has entered a period of agglomeration and development (Chen, 2010). During this period, due to the construction of the Wenchuan special tourist area, surrounding villagers poured into the town, and the urban space gathered quickly. However, due to geographical conditions, the urban spatial continuity is poor, and the city's center of gravity is shifted to Lehuo Village. At the same time, due to the development of road economy driven by tourism, a large number of residents build houses along the main roads and open farmhouses. The urban space of Sanjiang Town spreads along the main roads. The urban space is expanding rapidly (Tourism, 2008). In recent years, due to the gradual saturation of various constructions, the scale of cities and towns has entered a period of slow growth.

\subsubsection{Urban Reclamation Function: From Residential Domination to Tourism Domination}

Following the Wenchuan earthquake, the national and local governments, in order to restore the economy and society of the epicenter area, combined with local characteristics to implement the construction of a special tourist area in Wenchuan with commemorative and cultural themes. Combining with the development of Sanjiang Town's Pandar Scenic Area and Wenchuan Special Tour- 
ist Area, the tourism industry in Sanjiang Town has further developed, and the urban construction land is inclined to tourism land (Tourism, 2008; Wei, 2009).

\subsubsection{Spatial Form: From Scattered to Grouped}

The main settlements in Sanjiang Town were planned and reconstructed after the Wenchuan earthquake. The originally scattered rural settlements gathered in the center of the town sharply with the planned reconstruction. However, due to the three rivers converging in the center of the town and the scattered urban land, urban construction is subject to certain restrictions. And because Sanjiang Town is a multi-ethnic gathering place, in the early stage of planning and reconstruction, in order to protect the characteristics of different ethnic groups and the needs of tourism development, the urban settlements are divided into multiple groups, mainly divided into administrative offices, education and scientific research, mainly by the Han nationality. Commercial and residential market town center area group, farmhouse reception-oriented rural leisure and holiday group with good ecological environment, composed of tourist land, five-star hotels and tourism and leisure service group of Tusi Guanzhai and water village Tibetan village as the group The main entrance reception service area is composed of a group (Tourism, 2008; Wei, 2009; Ding, 2009).

\section{Analysis of Urban Spatial Development in Sanjiang Town}

The development of tourism in Sanjiang Town has not only brought opportunities for the development of Sanjiang Town's urban space, but also brought many challenges. This study found that Sanjiang Town's urban space still exists many problems through field investigations and questionnaire surveys and document collection. In this study, 90 questionnaires were distributed to Sanjiang Town, of which 86 were valid questionnaires. The questionnaire showed that the design of Sanjiang Town's park square was simple; the street space width was unreasonable; the location and quantity of public facilities were unreasonable and many other planning problems (Figure 1). In terms of riverside landscape development, there are problems such as simple construction and lack of central landscape; inconvenient use of seats and trash cans; less greening and poor environment (Figure 2). Its urban spatial characteristics are average, and the quality of the town needs to be improved urgently (Figure 3).

\subsection{Sanjiang Passes through the Market Town, and the Urban Space Security is Low}

Sanjiang Town is located between the Longmen Mountain System and the Qionglai Mountain System. The town is surrounded by high mountains and the terrain is undulating. The West River, Zhonghe River, and Heishi River divide the urban space and converge in the middle of the town and flow out eastward to form the Shoujiang River (Chen, 2010). Cities and towns have a lot of land adjacent to water, the rivers are undulating, the rivers are turbulent in the rainy season, 
In your opinion, what are the problems in the construction of the riverside landscape in Sanjiang Town? (Multiple choice)

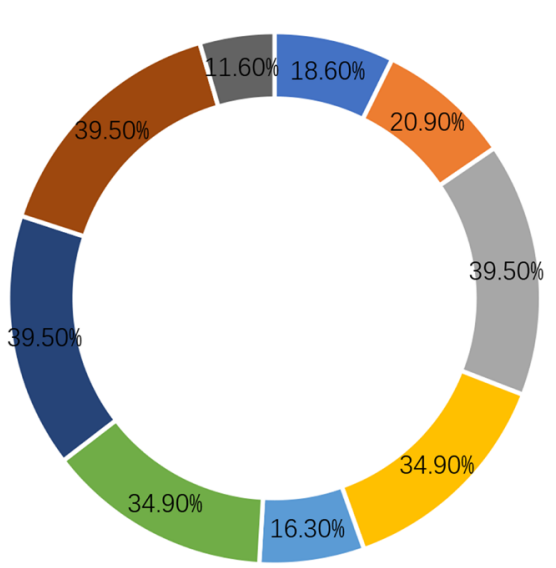

- Overall comfort and safety are poor

- The overall size is too small to meet the demand

- Simple construction, lack of central landscape

- Lack of innovation, no features

- The trail is too narrow to meet demand

- Less contact with water

- Inconvenient use of seats and trash cans

- Less greening and poor environment

- other

Figure 1. Questionnaire survey of existing problems in the urban spatial planning of Sanjiang Town.

In your opinion, what are the problems in the construction of the riverside landscape in Sanjiang Town? (Multiple choice)

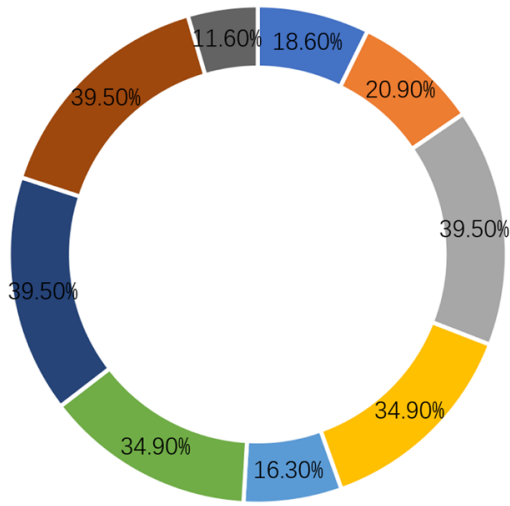

- Overall comfort and safety are poor

- The overall size is too small to meet the demand

- Simple construction, lack of central landscape

" Lack of innovation, no features

The trail is too narrow to meet demand

" Less contact with water

- Inconvenient use of seats and trash cans

- Less greening and poor environment

- other

Figure 2. Questionnaire survey of riverside landscape in Sanjiang town.

What do you think of the cultural characteristics of local residents in the planning and construction of Sanjiang Town?

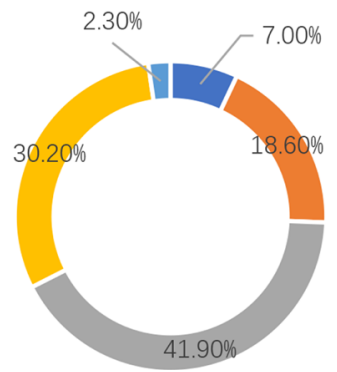

- Features are outstanding
- Features are more
prominent
- Features average
" Poor features
" Featureless

Figure 3. Questionnaire survey of town characteristics. 
the flood discharge capacity of the Shoujiang River is insufficient, and the revetment of the towns along the upper reaches of the river is not in place. After the floods in 2019, urban rivers were severely damaged, but they were not repaired in time, and the urban space security was low.

\subsection{Insufficient Urban Development Planning and Low Space Efficiency}

With the development of tourism in Sanjiang Town, the development of the town center is gradually lagging behind. Lehuo Village, dominated by the Water Village Zangzhai and Sanjiangli Health Care Center, has become the main body of economic construction and development, and the center of economic development of the township has gradually shifted to Lehuo Village. The towns and villages group with administrative functions as the main body and the sub-center group of Lehuo Village with tourism as the main body have been formed. Although the two are connected to a certain degree, they are far apart. In addition to the division of the river, the urban development has poor continuity, low land utilization, insufficient planning and management, poor landscape, and weak correlation, which makes it difficult to change the two groups. It is difficult to solve the current situation of inadequate connections between the towns and the development of scattered towns and low spatial efficiency.

\subsection{Fragmented Space and Poor Living Environment}

Sanjiang Town is one of the special tourist areas in Wenchuan, but the traffic conditions are relatively poor. Only Sanxuan Highway and one village road lead to the outside world. At the same time, three rivers converge in the town area, resulting in a loose distribution of residential areas. In order to make the urban space more closely connected, the management department planned to build a number of landscape nodes to increase the compactness of the urban space. However, the later management was not in place and affected by floods, the landscape nodes were dilapidated, the overall landscape of the town was weakened, and the compactness of the town was changed. At the same time, due to the vigorous development of urban space brought about by the development of the tourism industry, urban planning and construction are not sufficient to adapt to the development of cities and towns, lack of management, messy construction, poor living environment, and fragmented space.

\subsection{Uneven Distribution of Public Facilities and Public Space, Poor Quality of Towns}

Due to the rush of early planning and construction and the integration of tourism, cities and towns are gradually unable to keep up with the pace of urban development in terms of quality construction. Public management and public service facilities are in conflict between residents and tourists. The public facilities that were originally planned to only meet the needs of residents have become 
overwhelmed with the influx of tourists, and it is difficult to meet the spiritual and cultural needs of urban residents and tourists. In addition, Sanjiang Town, as a tourist town, has stagnated waterfront space improvement and ecological environmental protection, and economic and social development has not promoted the upgrading and change of urban quality.

\subsection{Insufficient Development and Protection of Waterfront Space}

Sanjiang meets three rivers, but Sanjiang has been on the verge of drying up for a long time. In recent years, Sanjiang Town has built a number of hydropower stations, destroying the water level and ecology of the river in Sanjiang Town. Due to the long-term dryness of the river course, large-flow floods when occasionally hit by heavy rains can easily cause the collapse of the river course, and cities and towns are more seriously threatened by rain and flood. The river bank has not been repaired due to flood damage, and the ecological environment is bad. Although there are slow walking trails along the river bank, the development of the riverside landscape and the river landscape is seriously insufficient, the viewability is poor, and the ecological environment is gradually deteriorating.

\section{Ideas for the Development of Tourist Towns under Rural Revitalization}

\subsection{Accelerate the Development of Industrial Integration and Promote the Diversification of Urban Development Power}

In the context of rural revitalization, the integration, coordination and innovative development of tourism-oriented town industries will become the key to urban development. For example, in Sanjiang Town, tourism is its leading industry, and it will still be the focus of urban industrial development in the future. However, under the influence of rural revitalization, Sanjiang Town, which has good agricultural advantages and AAAAA-level tourist attractions (Wang \& Li, 2018), should be based on the existing Based on the industry, fully tap its endogenous power source, take innovation as the guidance, and aim at integration and coordinated development, strengthen internal cultural excavation, and actively promote the integrated development of existing industries. Combining its own historical and cultural advantages, ecological resource advantages and agricultural advantages, vigorously tap its endogenous forces to provide new impetus for the integration and development of various industries.

\subsection{Change the Direction of Urban Development and Focus on the Development of Urban Local Culture}

Rural revitalization requires the goal of "prosperous industry, livable ecology, civilized rural style, effective governance, and affluent life" (Zhou \& Nie, 2020). In the development of villages and towns, it pays attention to the development of industry and the integration of urban and rural areas, harmonious coexistence between man and nature, and advancing with the times. In order to avoid the 
phenomenon of monolithic industries and extensive low-end development in township development. In the future, the development of tourist towns must avoid the low competitiveness caused by blind development. The situation of one thousand cities and the same scene of a thousand cities must also solve various urban spatial development problems such as insufficient development motivation. Therefore, cities and towns should actively promote the establishment of a benign urban development mechanism. Strengthen the management of urban space construction, promote urban renewal and development, and guide towns to form a compact, orderly, efficient, and high-quality urban spatial layout (Fang, 2014).

\subsection{Improve the Quality of Cities and Towns and Build Ecologically Civilized Tourist Towns}

In the context of rural revitalization, the development of tourist towns should pay more attention to the people-oriented concept, change the past blindly copying other town planning and development ideas, and pursue the problem of rapid urban development (The editorial, 2014). More should develop its internal resources, strengthen the excavation of its endogenous power, give the town a unique cultural connotation, give it a soul, and improve the quality of the town. Adjust measures to local conditions, strengthen the utilization and protection of the original ecological environment of cities and towns, realize the real ecological and livable sustainable development of cities and towns, and make them truly develop towards ecologically civilized cities and towns.

\section{Guidance on Urban Spatial Planning of Sanjiang Town}

Based on the above analysis and thinking about the development of tourist towns under rural revitalization, the urban spatial planning of Sanjiang Town can be guided from the following aspects.

\subsection{Planning a Guiding Strategy}

\subsubsection{Promote Urban Renewal and Strengthen Urban Functions}

In the context of rural revitalization, the urban space of Sanjiang Town is constantly expanding, and it is particularly important to strengthen the integration and renewal of its internal urban space and strengthen its functions. As an eco-tourism small town, its internal renewal and functional enhancement should be the main strategy of urban development for a period of time. It should fully respect the development of urban historical context, strengthen the construction and improvement of urban spatial functions, sort out the context of various urban systems, and optimize urban space layout, strengthens urban space management and control, improves the appearance of cities and towns along the streets, strengthens the main functions of cities and towns, and promotes the active renewal of urban spaces. Strengthen the management and protection of urban water environment, improve the quality of urban cultural space, strengthen 
the function of tourism land, and build a harmonious and livable ecologically civilized tourist town. Update the use efficiency of vacant land between the two groups, change the original loose land use dilemma, strengthen the related development between the groups, and enhance the integration of urban structure and development mode.

\subsubsection{Update Urban Public Service Facilities and Improve Urban Quality} Sanjiang Town is an ecological health tourism area in the Wenchuan Special Tourist Area. It should actively promote the construction and management of urban public service facilities and tourist facilities, riverside landscape space and urban leisure space, and enhance the quality of the town. Based on the current situation of urban space development, consideration can be given to combining the existing public service facilities in Jie Village with the new public service facilities in Lohas Village, increasing the construction of public service facilities in the riverside section, and renewing the construction of public service facilities in residential areas and various living spaces. Form a sound and complete system of public service facilities, strengthen the spatial connection of cities and towns, improve the quality of cities and towns, consolidate the infrastructure of small tourist towns, and promote the further development of tourism.

\subsubsection{Fully Excavate the Historical Culture of the Town, Protect and Inherit the Historical Context of the Town}

Sanjiang Town should fully actively explore the history and culture of the town, strengthen the construction of cultural connotation of small tourist towns, enrich the soul of the town, and improve the quality of the town (Li, 2009). According to relevant documents, Sanjiang Town has a profound historical and cultural heritage, but it has not been developed and utilized today (Zheng, 2009). Sanjiang Town should actively explore its cultural connotations such as Diqiang Culture, Ancient Tea Horse Road, Jiarong Tibetan Hometown Culture, Guanyin Pavilion, Taoist Culture, Guanjin Voucher Adventure Culture and other cultural connotations (Liao, 2013), combined with the Pandal Eco-tourism Scenic Spot to add urban cultural tourism loops, and collect folk Historical materials, protection of the existing Qiangqi, Lamasery and other historical relics (Zheng, 2009), construction of historical and cultural museums and other in-depth exploration of the historical and cultural connotation of the town, shape the cultural soul of tourist towns (Zhang, 2009), add the historical charm of the town, and enhance the quality of the town.

\subsection{Key Points of Planning and Layout}

\subsubsection{Full Coverage of Urban Space Control}

Based on the basic premise of people-oriented, ecological priority and environmental protection, make full use of the land between the two groups, connect the two groups, delimit the development boundary of towns and villages, delimit the living, ecological, and production spaces, and strictly delimit the implementation 
of prohibited areas, Restricted construction areas and suitable construction areas, protect the ecological background and basic farmland, and highlight the ecological nature of tourist towns. Propose corresponding space control measures, reasonably predict and control the scale of urban construction, guide the active, healthy and sustainable development of cities and towns, and avoid the disorderly spread of urban space.

\subsubsection{Township Function Integration and Space Optimization}

Renovate and renew some functions and environments of Jie Village and Lohas Villages and towns, strengthen different functional groups in towns and districts, and promote the healthy and sustainable development of cities and towns. It mainly strengthens the functions of the central district of the market town centered on administrative office, education, commerce and residence in Jie Village, and the function of the tourist entrance reception service area in Lehuo Village based on the water village Tibetan village. Actively promote the integration and complementarity of the two groups, and finally realize the integration and development of the two groups. Promote the development of farmhouses around Zangzhai Village, optimize the waterfront landscape environment, create waterfront tourism landscapes, increase waterfront tourism facilities and public service facilities, and promote the two groups to move closer to the middle and integrate development. Strengthen the connection between cities and towns, improve the lack of urban functions and the inequality of facilities.

\subsubsection{Historical and Cultural Protection and Urban Style Guidance}

It is necessary to fully respect the existing pattern and texture of the urban history, culture and historical region, deeply explore the characteristics of the urban history, culture and style (Wang, 2013), and strengthen the protection, utilization and inheritance of the Tibetan village and other historical relics in Sanjiang Town. Delimit the urban historical and cultural protection scope and style coordination area, with special attention to the coordination of the integration and development of the two groups. Focus on the spatial pattern of the city, mountains, and water of Sanjiang Town's eco-health tourism town, centering on the town's riverside landscape, water landscape, and mountain ecological landscape to form an eco-tourism with pleasant mountains and rivers, ecologically livable, and strong western Sichuan characteristics town landscape.

\subsubsection{Implement Timing Guidance}

In order to improve the status quo of urban space development and avoid disorderly expansion, it is necessary to proactively compile detailed project implementation rules with strong operability to form a reasonable short-term construction plan text. In the near future, Sanjiang Town should strengthen the development of the two groups in the middle of the group, the implementation of urban riverside landscape and river restoration projects, and realize the integration of urban development as soon as possible, and create a vibrant town center. 
The close development of the two groups will help to complement each other's advantages, strengthen the connection between cities and towns, and form a complete urban spatial system.

\section{Conclusion}

This article takes Sanjiang Town as an example, analyzes its spatial problems through the discussion of its spatial development history and characteristics, and proposes development strategies and spatial planning guidance measures based on the rural revitalization strategy.

The development of small tourist towns in my country has undergone vigorous development, slow development, and then endogenous development. Urban space problems have become prominent. Under the background of rural revitalization, the development of small towns is facing major changes. The implementation of the rural revitalization strategy will become an effective way on this reform line. For small tourist towns, promoting the integrated development of urban industries and the coordinated development of urban space is an important strategy for the implementation of rural revitalization. The concept of urban spatial development must be adhered to, combined with their own characteristics and advantageous resources, to fully tap the town's endogenous driving force, and strengthen the countryside. Study the concept of revitalization, and constantly update the urban planning ideas and development strategies, so as to promote the sustainable development of tourist towns.

\section{Conflicts of Interest}

The authors declare no conflicts of interest regarding the publication of this paper.

\section{References}

(2018). Seminar on the Practice of Rural Revitalization in Big Cities. Urban and Rural Planning, No. 5, 79-118.

(2018). Tourism and Urban-Rural Planning and Design Institute of Southwest University for Nationalities. The Master Plan of the Sanjiang Scenic Area in Wenchuan County, No. 9.

Chen, K. (2010). Post-Disaster Ecotourism Development Research of Wenchuan Sanjiang Scenic Area. China University of Geosciences.

Ding, X. (2009). Thoughts on the Current Situation and Planning of Water Supply and Drainage Facilities in Sanjiang Township, Wenchuan County, Sichuan Province. Western Development (Mid-Term), No. 12, 38-38, 79.

Fang, C. (2014). Important Progress and Future Development Directions in the Study of Urban Agglomerations in China. Acta Geographica Sinica, No. 8, 1130-1144.

Liao, G. (2013). Ideas for the Construction of Low-Carbon Tourist Attractions: Taking Wenchuan Sanjiang Ecological Tourist Area as an Example. Journal of Aba Teachers College, 30, 48-51. https://doi.org/10.3969/j.issn.1008-4142.2013.03.010

Liu, Y., Zhou, Y., \& Li, Y. (2019). China’s Rural Regional System and Rural Revitalization 
Strategy. Acta Geographica Sinica, No. 12, 2511-2528.

Li, Y. (2009). The Soul and God of Sanjiang Township in Wenchuan. Journal of Aba Teachers College, 26, 29-33. https://doi.org/10.3969/j.issn.1008-4142.2009.03.008

Pan, W. (2000). Research on the Development of Ecotourism in Western Sichuan Mountainous Area-Taking Wenchuan Sanjiang Ecotourism Area as an Example. Chengdu University of Technology.

Sanjiang Town People’s Government. (2021). Sanjiang Town (No. 5, p. 6). Wenchuan County People's Government.

Tao, T., \& Qiu, T. (2014). Reasonable Positioning, Comprehensive Utilization, and Integration of Production and City-Discussion on New Ideas for the Revision of the Overall Planning of Small Towns in Southern Jiangsu under the Background of New Urbanization. Small Town Development, No. 12, 34-45.

The Editorial Department of This Journal (2014). Summary of Speeches at the Symposium on New Urbanization. Urban Planning Journal, No. 1, 1-8.

Wang, W., \& Li, G. (2018). Research on the Development Problems and Countermeasures of Country House Clusters under the Background of Rural Tourism Transformation and Upgrading-Taking Sanjiang Town, Wenchuan County as an Example. Sichuan Agricultural Science and Technology, No. 4, 70-71. https://doi.org/10.3969/j.issn.1004-1028.2018.04.029

Wang, J. (2013). Characteristic Shaping and Planning Control Guidance of Mountainous Towns-Analysis of Urban Characteristic Planning of Yongping, Yunnan. Small Town Development, No. 11, 98-104.

Wei, M. (2009). The Construction of Tourism Development Pattern in Sanjiang Township, Wenchuan County after the Earthquake. Journal of Aba Teachers College, 26, 2931, 35. https://doi.org/10.3969/j.issn.1008-4142.2009.04.009

Zhang, G. (2009). Activating Oxygen to Condense the Sanjiang Human Health groundOn the Ecological Advantages of Wenchuan Sanjiang Scenic Area. Journal of Aba Teachers College, 26, 34-37. https://doi.org/10.3969/j.issn.1008-4142.2009.03.009

Zhang, J. (2020). Research on Small Tourist Towns in Ethnic Areas in the Upper Reaches of the Minjiang River. Southwest University for Nationalities.

Zheng, Z. (2009). Sanjiang Panlong Mountain and Ancient Shu Culture Investigation. Journal of Aba Teachers College, 26, 25-28.

https://doi.org/10.3969/j.issn.1008-4142.2009.04.008

Zhou, X., \& Nie, K. (2020). Research on the Development Characteristics of the Core Elements of Rural Revitalization under the Background of Spatial Planning-Taking the Rural Revitalization Plan of Xichang City as an Example. Small Town Development, No. 5, 57-62. 